\title{
Complex Dielectric Properties of Microcrystalline Cellulose, Anhydrous Lactose, and $\alpha$-Lactose Monohydrate Powders Using a Microwave-based Open-reflection Resonator Sensor
}

\author{
PEI-FANG SUNG, ${ }^{1}$ YI-LING HSIEH, ${ }^{2}$ KRISTEN ANGONESE, ${ }^{3}$ DON DUNN,${ }^{4}$ RAY J. KING, ${ }^{4}$ RACHEL MACHBITZ, ${ }^{1}$ \\ ANDREW CHRISTIANSON, ${ }^{5}$ WILLIAM J. CHAPPELL, ${ }^{5}$ LYNNE S. TAYLOR, $^{2}$ MICHAEL T. HARRIS ${ }^{1}$ \\ ${ }^{1}$ Department of Chemical Engineering, Purdue University, West Lafayette, Indiana 47907 \\ ${ }^{2}$ Department of Industrial and Physical Pharmacy, Purdue University, West Lafayette, Indiana 47907 \\ ${ }^{3}$ Department of Chemical Engineering, University of Michigan, Ann Arbor, Michigan 48109 \\ ${ }^{4}$ KDC Technology Corporation, Livermore, California 94550 \\ ${ }^{5}$ Department of Electrical and Computer Engineering, Purdue University, West Lafayette, Indiana 47907
}

Received 12 August 2010; revised 5 January 2010; accepted 19 January 2011

Published online 16 February 2011 in Wiley Online Library (wileyonlinelibrary.com). DOI 10.1002/jps.22516

\begin{abstract}
The real $\left(\varepsilon^{\prime}\right)$ and imaginary $\left(\varepsilon^{\prime \prime}\right)$ components of the complex permittivity of anhydrous lactose and microcrystalline cellulose (MCC) under different bulk densities, moisture contents (MCs), and times of hydration (for anhydrous lactose) were measured nondestructively using a microwave resonator sensor operating in the range of 700-800 MHz. Measurements of sensor resonant frequency and conductance allow, through calibration, determination of the complex dielectric properties $\varepsilon^{\prime}$ (relative permittivity) and $\varepsilon^{\prime \prime}$ (relative dielectric loss) of the test material. Characteristic graphs of $\varepsilon^{\prime \prime}$ versus $\varepsilon^{\prime}-1$ curve for each powder were generated as a function of bulk density and MC. Such data can be used to develop empirical models for the simultaneous in situ measurement of the bulk density and MC of the powders. Unlike MCC, anhydrous lactose is converted to its hydrate form in the presence of moisture, which causes a reduction in the amount of physisorbed and "free" water and a subsequent change in the dielectric properties. For powders such as anhydrous lactose that can form a crystal hydrate in the presence of moisture, a combination of techniques such as vibrational spectroscopy together with microwave resonator measurements are appropriate to characterize, in situ, the physical and chemical properties of the powder. @ 2011 Wiley-Liss, Inc. and the American Pharmacists Association J Pharm Sci 100:2920-2934, 2011
\end{abstract}

Keywords: hydrate; moisture sorption; water in solids; drying; powder technology

\section{INTRODUCTION}

Lactose and microcrystalline cellulose (MCC) are among the most commonly used excipients in the pharmaceutical industry. MCC is a partially crystalline, highly compressible material, which can produce hard tablets. Although MCC is insoluble in water, it is hygroscopic as a result of the presence of disordered regions that can absorb moisture. ${ }^{1}$ Lactose, which is cheaper, has higher compatibility and is easily dissolved in water. ${ }^{2}$ There are several crys-

Correspondence to: Michael T. Harris (Telephone: 253-241-8087; Fax: 765-494-0805; E-mail: mtharris@purdue.edu)

Journal of Pharmaceutical Sciences, Vol. 100, 2920-2934 (2011)

(c) 2011 Wiley-Liss, Inc. and the American Pharmacists Association talline forms and it can also be made amorphous and partially amorphous through spray drying. The most common crystalline forms are $\beta$-lactose anhydrous (termed anhydrous lactose herein) and $\alpha$ lactose monohydrate. ${ }^{3}$ There is a need to accurately measure the bulk density and moisture content (MC) of these two powders in order to assure tablet quality; hence, this paper focuses on the use of a microwave resonator sensor to characterize their intrinsic complex dielectric properties under different moisture and density conditions.

In the pharmaceutical industry, bulk density and MC are two of the most important information indicators for powder flowability and compressibility. The gravimetric method and loss on drying (LOD) method 
are the simplest ways to determine the bulk density and MC of a powder, respectively; however, these two techniques are intrusive, involve subsampling, and are not practical for real-time measurements. Use of electrical properties to indirectly estimate the physical properties of the material has therefore gained much popularity. Among the techniques that are used to measure the electrical properties, microwave-based sensors provide a nondestructive and real-time technique for the characterization of materials. They have been used to determine the MC of materials in many industries due to their capability to show very strong contrast between water and low dielectric host materials such as anhydrous lactose and MCC. . $^{4-9}$

There are several types of sensors used in microwave technology. ${ }^{5,7}$ Trabelsi et al. ${ }^{8}$ used a freespace transmission technique to measure the permittivity of wheat. They observed linear relations between the normalized dielectric properties in plots of $\varepsilon^{\prime \prime}$ versus $\varepsilon^{\prime}$ (also known as Argand diagrams) at different frequencies and different temperatures. King ${ }^{9-11}$ also has applied both open-reflection resonator and transmission microwave sensor systems for online measurements of moisture and density in industrial applications.

Dielectric properties are intrinsic properties of a material that are represented by the complex permittivity:

$$
\tilde{\varepsilon}=\varepsilon_{0}\left(\varepsilon^{\prime}-\varepsilon^{\prime \prime} j\right)
$$

where $j=\sqrt{-1}, \varepsilon_{0}$ is vacuum permittivity $8.854 \times$ $10^{-12} \mathrm{~F} / \mathrm{m}, \varepsilon_{0} \varepsilon^{\prime}$ (dielectric constant) relates to the ability of the material to store the electric energy, and $\varepsilon_{0} \varepsilon^{\prime \prime}$ (loss factor) relates to the dissipation of the energy when the material is exposed to an external electric field. Both the dielectric constant and the loss factor are functions of the frequency of the external field, bulk density, MC, and temperature of the powder. ${ }^{4,8-13}$ Note, as is customary, data will be presented in terms of relative dielectric values $\varepsilon^{\prime}$ and $\varepsilon^{\prime \prime}$.

In this paper, data from measurements of the dielectric properties of two powders (MCC and anhydrous lactose) at room temperature with different bulk densities and MCs are presented in graphs of $\varepsilon^{\prime}$ versus $\varepsilon^{\prime}-1$. The sensor used to acquire the data was a highly sensitive open-reflection microwave resonator.

Water can form different types of interaction with the powder depending on the chemical and physical properties of the latter, thus affecting the bulk dielectric properties. ${ }^{14}$ Water added to MCC powder either remains as free water or becomes physisorbed through interaction with the surface (either external surface or pores) and disordered regions. In our research, the bulk water that was initially added into the powder was called free water. Because free water has a high dielectric constant, $\varepsilon^{\prime}$ approximately 80 at $75^{\circ} \mathrm{F}^{13}$ in the frequency range of $700-800 \mathrm{MHz}$, a small amount when added to MCC can have a dramatic effect on the dielectric properties. With time, some of these water molecules will "physisorb" onto the powder surface and will be absorbed into the bulk structure, retaining a high mobility and therefore responding to the electromagnetic waves. In contrast, water added to anhydrous lactose results in hydration and conversion of anhydrous lactose to lactose monohydrate; the added water of hydration becomes molecularly bound through incorporation into the crystal lattice and herein will be referred to as crystallographic water.

\section{THEORY}

The microwave sensor being used in this research was an open-reflection resonator sensor, a commercial product designed and manufactured by KDC Technology Corporation. Resonant sensors are more accurate in the dielectric properties measurement in comparison with a nonresonant sensors. ${ }^{15}$ The sensor was calibrated at the factory using dielectric standards to allow determination of $\varepsilon^{\prime}$ and $\varepsilon^{\prime \prime}$ from measurements of sensor resonant frequency and conductance.The resonant frequency and conductance of the sensor was determined by measuring the sensor reflection coefficient over a range of frequencies. The dielectric calibration equations unique to this sensor and provided by KDC are:

$$
\begin{gathered}
\varepsilon^{\prime}=1+10.747\left[\left(\frac{f_{\mathrm{r}, 0}}{f_{\mathrm{r}}}\right)^{2}-1\right] \\
\varepsilon^{\prime \prime}=158.7\left(\frac{g-g_{\text {air }} / \sqrt{\varepsilon^{\prime}}}{f_{\mathrm{r}}}\right)
\end{gathered}
$$

where $f_{\mathrm{r}, 0}$ and $g_{\text {air }}$ are the measured sensor resonant frequency and conductance in air, respectively, and $f_{\mathrm{r}}$ and $g$ are the resonant frequency and conductance of the sensor, respectively, when interfaced to the test material. Reference ${ }^{11}$ provides insight into the derivation of equations similar to the one given above. Sensor "zeroing" is accomplished by making a reference measurement in air. During an experiment, changes in the resonant frequency and conductivity of the sensor with the introduction of the sample were determined from measurements of the sensor reflection coefficient using a network analyzer, from which $\varepsilon^{\prime}$ and $\varepsilon^{\prime \prime}$ were determined using Eqns. (2) and (3). Graphs of the $\varepsilon^{\prime \prime}$ versus $\varepsilon^{\prime}-1$ curve were generated 


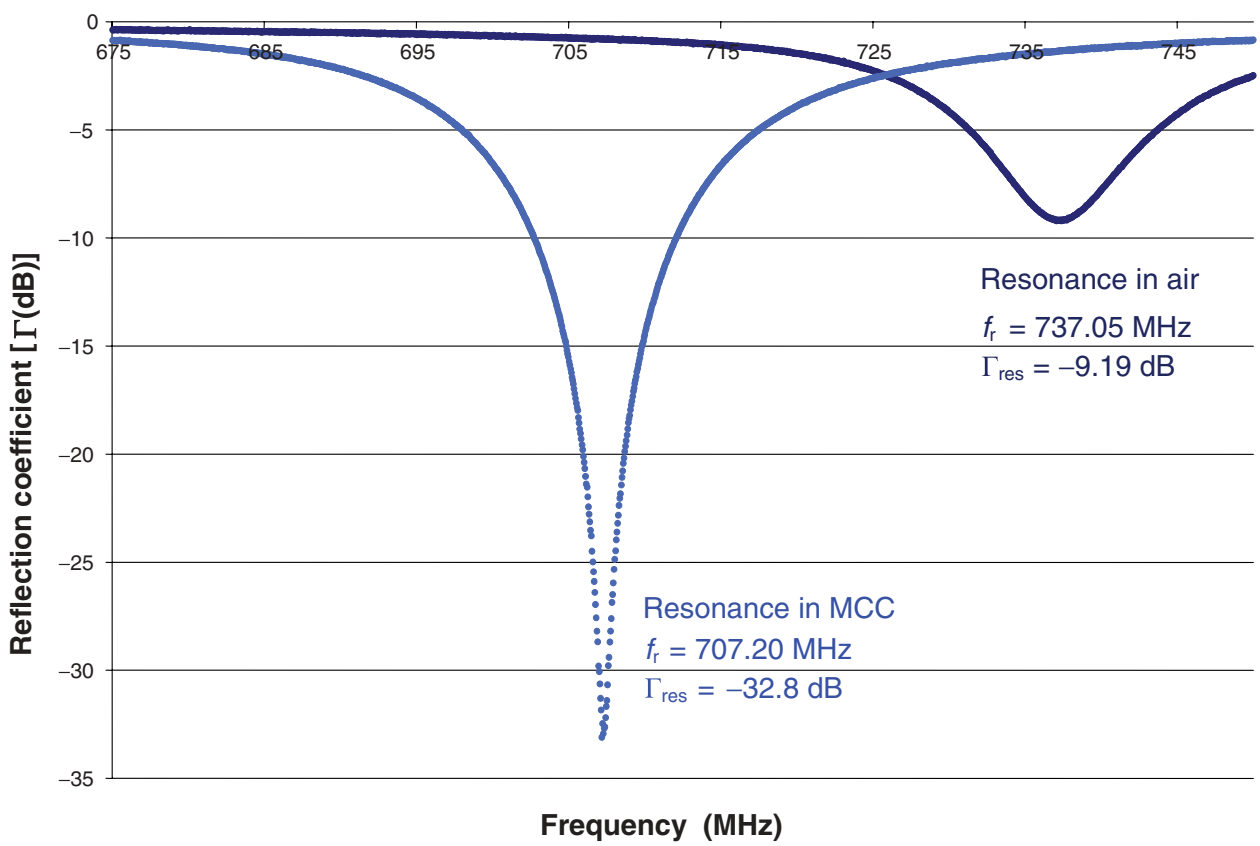

Figure 1. Example of sensor resonance measurements for microcrystalline cellulose (MCC).

from measurements on the product at constant MC but with varying bulk densities.

Example of resonance curves of reflection coefficient $\Gamma(\mathrm{dB})$ versus frequency $(\mathrm{MHz})$ are shown in Figure 1 for the sensor in air and in contact with MCC product. The resonant frequency occurs when the magnitude is a minimum, denoted $\Gamma_{\text {res }}$ in Figure 1 . The measured conductance is related to amplitude $\Gamma_{\text {res }}$ by:

$$
\begin{aligned}
& g=\frac{\left(1-\Gamma_{\text {res }}\right)}{\left(1+\Gamma_{\text {res }}\right)} \quad(\text { sensor coupling overcoupled }) \\
& g=\frac{\left(1+\Gamma_{\text {res }}\right)}{\left(1-\Gamma_{\text {res }}\right)} \quad(\text { sensor coupling undercoupled) }
\end{aligned}
$$

where $\Gamma_{\text {res }}=10^{-(|\Gamma \mathrm{dB}| / 20)}$ and $0<\Gamma_{\text {res }}<1$ (Ref. $\left.{ }^{11}\right)$.

\section{MATERIALS AND EXPERIMENTAL SETUP}

The resonant frequency and conductance of a microwave resonant sensor, when loaded with MCC (Avicel PH105, FMC Biopolymer, Philadelphia, PA., USA) or anhydrous lactose (DT51808TT, Sheffield Pharma, Norwich, NY., USA) were measured under different bulk densities and MCs using a network analyzer (Agilent/HP 8752C, 300KHz-1.3GHz, Agilent Technologies, Inc., Santa Clara, CA., USA). A resonator sensor (SN0909-7, KDC Technology Corporation, Livermore, California) connected to the analyzer was placed under the powder to measure the powder's dielectric properties. Figure 2 shows the experimental setup for the dielectric properties measurement. The microwave resonator sensor must be in intimate contact with the material being tested. Here the sensor was mounted in a 1 square foot stainless steel plate, and the material was poured into a cylindrical acrylic sample holder(McMaster-Carr, Santa Fe Spring, CA., USA) that spanned the sensor sensing area. This setup ensured intimate contact between the sensor face and the material (i.e., precluded air gaps between the powder and the sensor face). This arrangement also avoided bulk density variations that could occur if the sensor was mounted on top of the powder.

The powder was passed through a sieve (mesh size $\sim 1 \mathrm{~mm}$ ) before the dielectric properties measurements to control the size distrubution of the particles

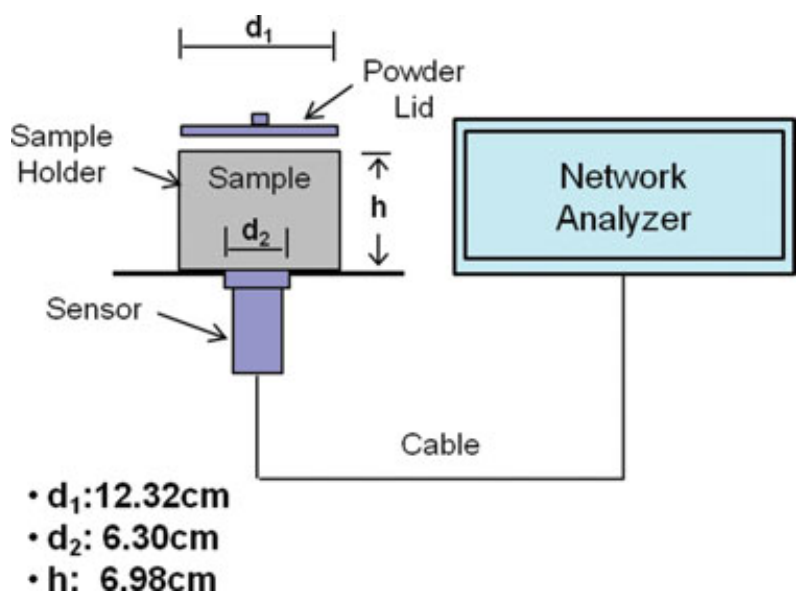

Figure 2. The experimental setup for the dielectric properties measurement. 
in the powder. This step was important especially when the powder was wetted because smaller particles tended to agglomerate into larger granules in the presence of water. Powders not being measured stayed sealed in a zip-locked plastic bag. The bulk density of the powder was changed by tapping the sample holder. An acrylic lid was placed on top of the powder to create a flatter surface for more accurate calculation of the powder volume. After the resonant frequencies and conductance under different bulk densities were measured, all of the powder inside the sample holder were collected to measure the total mass.

The bulk density of a powder sample is defined as follows:

$$
\rho=\frac{m_{\mathrm{w}}+m_{\mathrm{p}}}{V_{\mathrm{total}}}
$$

where $r$ is the bulk density of the powder, $m_{\mathrm{w}}$ is the mass of the water, $m_{\mathrm{p}}$ is the mass of the powder, and $V_{\text {total }}$ is the entire volume of the powder sample. Bulk densities were calculated at the end of the dielectric properties measurement after the total mass $\left(m_{\mathrm{w}}+\right.$ $m_{\mathrm{p}}$ ) was weighed. The range of the bulk densities and the total mass weighed for each powder during each measurement will be shown together with the results in the later section.

To study the MC effect on the dielectric properties, samples with different MCs were prepared by exposing the powder to steam.

A balance was used to monitor the approximate total weight change when moisture was absorbed into the powder. The wetted powder was then stirred and mixed well and finally sealed in three zip-locked bags. Each bag was opened at the time of the dielectric properties measurements of the powder. The real MC for each wetted powder was measured using the LOD method and is defined as follows:

$$
\mathrm{MC}=\frac{m_{\mathrm{w}}}{m_{\mathrm{w}}+m_{\mathrm{p}}} \times 100 \%
$$

Note that this MC represents the "total moisture (free or physisorbed water + crystallographic water)" existing in the powder. Every time the powder was poured onto the sensor surface for the dielectric properties measurements, a small sample of the powder was taken and heated to $100 \pm 10^{\circ} \mathrm{C}$ and held in this temperature range for 1 day for the MC measurement. This LOD method was validated by measuring the MC of anhydrous lactose and $\alpha$-lactose monohydrate powders as received from the vendor. Using the LOD method where the powder is held in the temperature range of $100 \pm 10^{\circ} \mathrm{C}$ for 1 day, the $\mathrm{MC}$ of $\alpha$ lactose monohydrate, as purchased from the vendor, was $5.25 \pm 0.1 \%$, which agrees with the theoretical MC (5\% of crystallographic water) of $\alpha$-lactose mono- hydrate. The measured MC for the anhydrous lactose was $0.65 \pm 0.03 \%$, whereas the vendor reported a MC of $0.5 \%$ for this powder. Thus, this LOD method was used to measure the MC of the powders in this study. The bulk densities and MC of the powders measured using the gravimetric method and LOD method, respectively, were then related to the dielectric properties $\varepsilon^{\prime \prime}$ and $\varepsilon^{\prime}$ through Argand diagrams.

Triplicate dielectric property measurements of each of three samples were made for powders with the same MC to calculate a standard deviation of the dielectric property values. The powder was compressed from the pour bulk density to increase its bulk density. Previously compressed powder was not recycled in the measurement of the dielectric properties to minimize variability in the data due to bulk density variability in such powders. The dielectric properties measurements were taken at constant MC because performing the measurements at constant bulk density was difficult to achieve.

In addition to dielectric measurements, Raman spectroscopy was utilized to detect formation of $\alpha$ lactose monohydrate in the initially anhydrous lactose samples. Raman spectroscopy is sensitive in detecting changes in crystal form. ${ }^{16}$ Raman spectra were obtained using a RamanRxn1-785 Raman spectrometer (Kaiser Optical Systems Inc., Ann Arbor, Michigan) with a 785-nm excitation laser. The system is equipped with fiber optics attached to a noncontact MR(multiple reactor) sampling probe with a spot size of $150 \mu \mathrm{m}$. The total exposure time during acquisition for each sample was $100 \mathrm{~s}$ using $200 \mathrm{~mW}$ laser power. A calibration plot was generated by obtaining sample spectra for binary mixtures of anhydrous $/ \alpha$-lactose monohydrate at five different molar ratios prepared by trituration. Samples were analyzed in triplicate.

\section{EXPERIMENTAL RESULTS}

\section{The Relationship Between $\varepsilon^{\prime \prime}$ and $\varepsilon^{\prime}-1$ for Anhydrous Lactose and MCC}

A linear relationship was found between $\varepsilon^{\prime \prime}$ and $\varepsilon^{\prime}$ - 1 for anhydrous lactose and dried MCC as shown in Figures 3 and 4 as a function of bulk density. As expected, the graphs show that the dielectric values increase with increasing density. The anhydrous lactose removed from the drum contains an approximate $\mathrm{MC}$ of $0.65 \%$, whereas MCC was heated to achieve an approximate $\mathrm{MC}$ of $0.40 \%$..

Meyer and Schilz ${ }^{17}$ also concluded that the ratio of $\varepsilon^{\prime \prime}$ and $\varepsilon^{\prime}-1$ should be a function of MC only if both $\varepsilon^{\prime \prime}$ and $\varepsilon^{\prime}-1$ are similar functions of the bulk densities. By inspecting our data, we found that $\varepsilon^{\prime \prime}$ and $\varepsilon^{\prime}-1$ increase with bulk densities in a similar way, and a linear relation between $\varepsilon^{\prime \prime}$ and $\varepsilon^{\prime}-1$ for a constant MC indeed exists within the range of bulk densities 


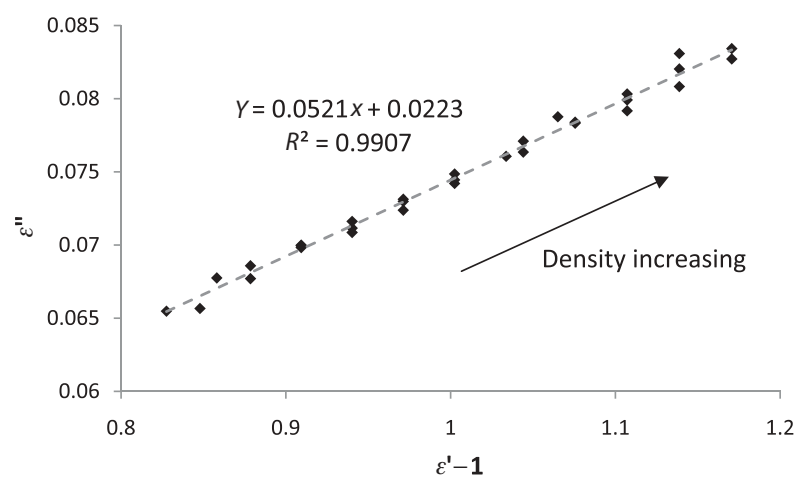

Figure 3. The relationship between $\varepsilon^{\prime \prime}$ and $\varepsilon^{\prime}-1$ of $\mathrm{MC}=$ $0.65 \%$ anhydrous lactose $\left(f_{\mathrm{r}}=700-740 \mathrm{MHz}\right.$, nominally, $75^{\circ} \mathrm{F}$ ); bulk densities range from 0.57 to $0.83 \mathrm{~g} / \mathrm{cm}^{3}$, total sample mass for these triplicates are 490,479 , and $474 \mathrm{~g}$.

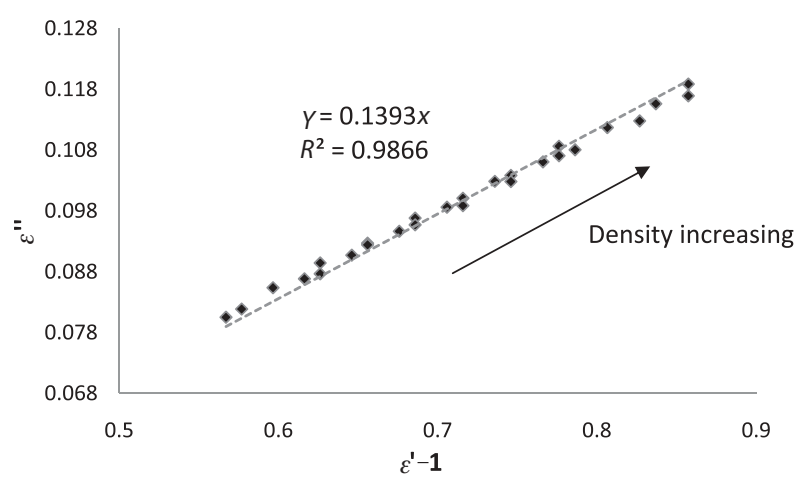

Figure 4. The relationship between $\varepsilon^{\prime \prime}$ and $\varepsilon^{\prime}-1$ of $\mathrm{MC}=$ $0.40 \% \mathrm{MCC}\left(f_{\mathrm{r}}=700-740 \mathrm{MHz}\right.$, nominally, $\left.75^{\circ} \mathrm{F}\right)$; bulk densities range from 0.34 to $0.56 \mathrm{~g} / \mathrm{cm}^{3}$, total sample mass for these triplicates are 288, 249, and $286 \mathrm{~g}$.

encompassed by our samples. Furthermore, the slope of this linear curve is a function of the MC, as will be demonstrated below

\section{Dielectric Properties of Wetted Anhydrous Lactose: Conversion of Anhydrous Lactose to $\alpha$-Lactose Monohydrate}

Anhydrous lactose is converted into a hydrate form in the presence of moisture. ${ }^{18,19}$ The conversion affects the dielectric properties measurement as is shown in this section, and therefore, monitoring $\varepsilon^{\prime \prime}$ and $\varepsilon^{\prime}$ as a function of time is a potential method for quantifying the conversion rate of anhydrous lactose to $\alpha$-lactose
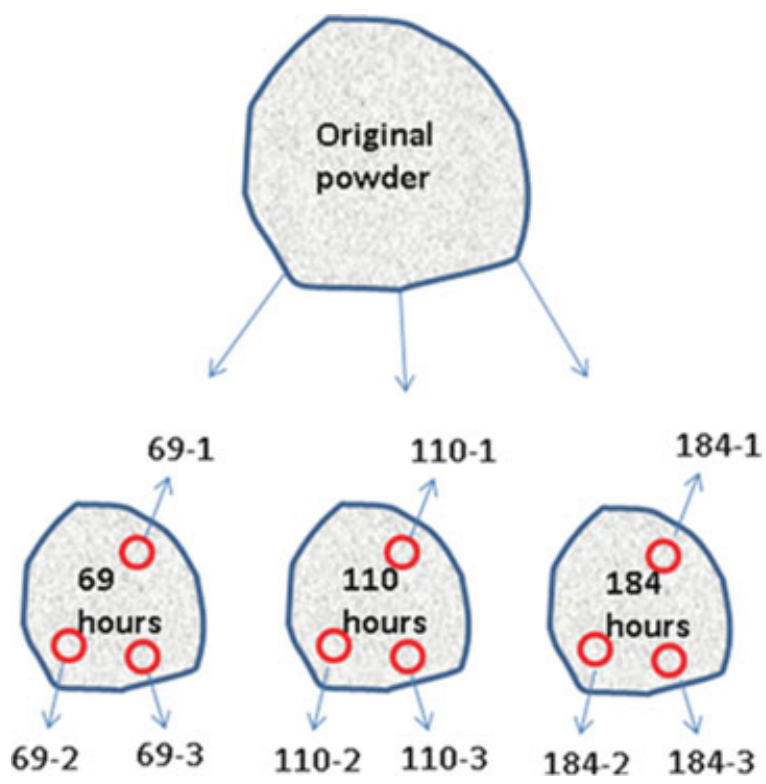

Figure 5. Sketch of the powder sampling for the moisture content measurement.

monohydrate. In the experiment, anhydrous lactose was wetted and the temporal variation in the dielectric properties of the wetted powder was measured. The wetted powder was divided into three bags. The dielectric properties of the powder in the first, second, and third bags were measured after 69,110 , and $184 \mathrm{~h}$, respectively. The uniformity of the $\mathrm{MC}$ inside the wetted powder was determined by taking samples from nine different locations inside the bulk sample and subsequently heating the samples at $100 \pm 10^{\circ} \mathrm{C}$ for 1 day. The definitions of the sample identifications are shown in Figure 5 and the MC results are given in Table 1. Note that all the MC values represent the water that was added plus the amount of water $(0.65 \%)$ that was already in the purchased powders.

The MC of the powder (Table 1) ranged from $2.39 \%$ to $2.56 \%$ with an average of $2.5 \%$ and standard deviation of $0.058 \%$. The relations between $\varepsilon^{\prime \prime}$ and $\varepsilon^{\prime}-1$ for powder samples taken at 69,110 , and $184 \mathrm{~h}$ are shown in Figure 6. The sampling time (or conversion time in the case of anhydrous lactose powder) is the period from the addition of moisture to the powder to the measurement of the dielectric properties of the powder. For this MC, the values of $\varepsilon^{\prime}$ and $\varepsilon^{\prime \prime}$ decreased with an increase in the conversion time.

Table 1. Moisture Content Measured in Different Locations After One Moisture Sample Preparation for Anhydrous Lactose

\begin{tabular}{rccccccccc}
\hline & $69-1$ & $69-2$ & $69-3$ & $110-1$ & $110-2$ & $110-3$ & $184-1$ & $184-2$ & $184-3$ \\
\hline MC & $2.48 \%$ & $2.54 \%$ & $2.39 \%$ & $2.56 \%$ & $2.54 \%$ & $2.42 \%$ & $2.50 \%$ & $2.54 \%$ & $2.49 \%$ \\
MC & Average of 69 -h bag: $2.47 \%$ & Average of 110 -h bag: $2.51 \%$ & Average of 184-h bag: $2.51 \%$ \\
\hline
\end{tabular}

Average of the entire original bag: $2.50 \%$.

Note: The $a-b(69-1,69-2$, etc. .) designation in Table 1 represents (number of equilibrium hours)-(replicate sample number). Each heating duration was at least $5 \mathrm{~h}$ and the temperature was about $90^{\circ} \mathrm{C}-110^{\circ} \mathrm{C}$. 


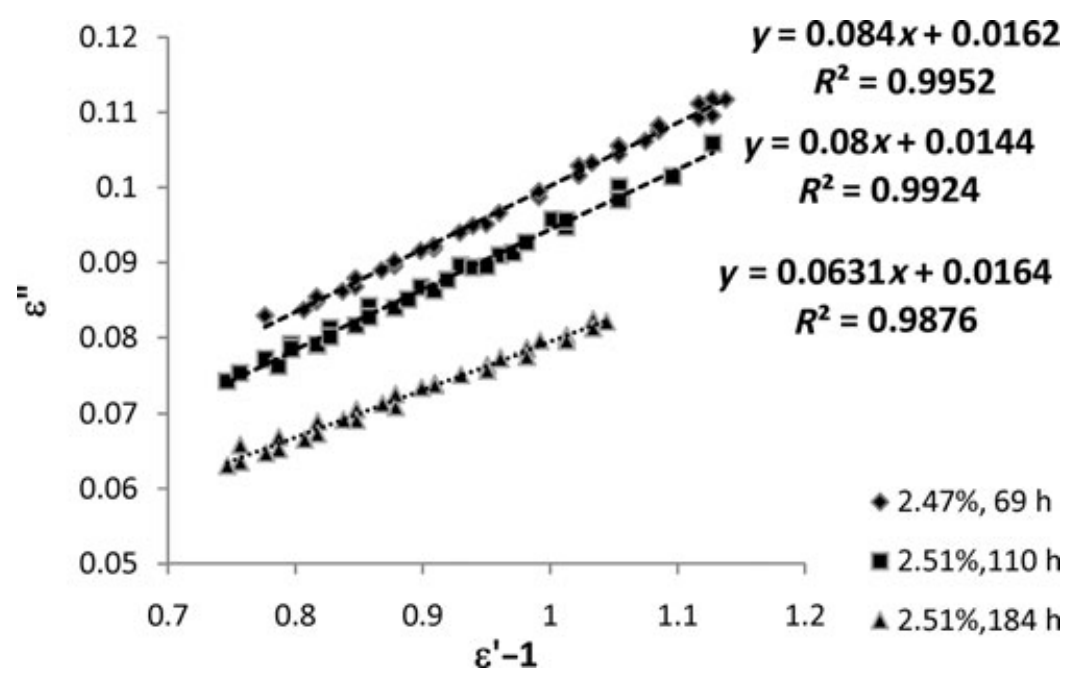

Figure 6. The relationship between $\varepsilon^{\prime \prime}$ and $\varepsilon^{\prime}-1$ for lactose under $\mathrm{MC}=2.50 \%$, measured different days after being added moisture with density varying $\left(f_{\mathrm{r}}=700-740 \mathrm{MHz}\right.$, nominally, $\left.75^{\circ} \mathrm{F}\right)$; bulk densities range: at $69 \mathrm{~h}, 0.50-0.75 \mathrm{~g} / \mathrm{cm}^{3}$; at $110 \mathrm{~h}: 0.50-0.76 \mathrm{~g} / \mathrm{cm}^{3}$; at $184 \mathrm{~h}: 0.51-0.75 \mathrm{~g} /$ $\mathrm{cm}^{3}$.

As the anhydrous lactose undergoes conversion to the crystalline hydrate form, the water added becomes incorporated into the crystal lattice, becoming "water of crystallization" with a much lower degree of mobility. Even though the amount of total water (free or physisorbed + crystallographic) remained constant, $\varepsilon^{\prime \prime}$ and $\varepsilon^{\prime}$ of the material decreased with time because crystallographic water is not as easily rotated in an electromagnetic field as either physisorbed or free water. Crystallographic water has a much less effect on bulk dielectric properties than physisorbed or free water. ${ }^{14}$

Although the samples used to generate the curves in Figure 6 have almost the same total MC, results of Raman analysis (vide infra) confirm that they have different amounts of physisorbed and "free" water; therefore, the $\varepsilon^{\prime \prime}$ values are lowered over time as the lactose converts to the monohydrate form, decreasing the amount of more mobile water. The slopes of the curves in Figure 6 are also related to the degree of hydration. As more and more physisorbed and "free" water is being converted to crystallographic water, the slopes must decrease.

Figure 7 shows the relationship between $\varepsilon^{\prime \prime}$ and $\varepsilon^{\prime}$ - 1 at different MCs. These samples with different MCs were measured at the same conversion time (in Fig. 7, the conversion time is about $110-111 \mathrm{~h}$ ). The $\varepsilon^{\prime \prime}$ and $\varepsilon^{\prime}-1$ curve for lactose of MC $=0.65 \%$ is the anhydrous lactose removed from the drum. Note that this graph is different from Figure 6 because Figure 6 shows the curves for "different conversion times" at the same total MC In Figure 7, each point represents one bulk density value, and the slope of the $\varepsilon^{\prime \prime}$ versus $\varepsilon^{\prime}-1$ curve increases with an increase in the MC. An empirical calibration to the MC is possible, although additional data would be required because the calibration would likely be nonlinear.

The fits of linear regress analysis to the data displayed in Figure 7 and the bulk density range for each curve are shown in Table 2.

In Figure 7, the dielectric properties of $\alpha$-lactose monohydrate are compared with those of the dried anhydrous lactose. The original $\alpha$-lactose monohydrate taken out from the drum without being heated or wetted contains about $\mathrm{MC}=5.25 \%$. Of significance is that, the $\varepsilon^{\prime \prime}$ versus $\varepsilon^{\prime}-1$ curve for $\alpha$-lactose monohydrate overlaps, within the experimental error, with the $\varepsilon^{\prime \prime}$ and $\varepsilon^{\prime}-1$ curve for $\mathrm{MC}=0.09 \%$ anhydrous lactose. This was unexpected because these two products have different crystalline structures.

Figure 8 shows dielectric properties data for anhydrous lactose powders with $0.65 \% \mathrm{MC}, 1.99 \% \mathrm{MC}$ at

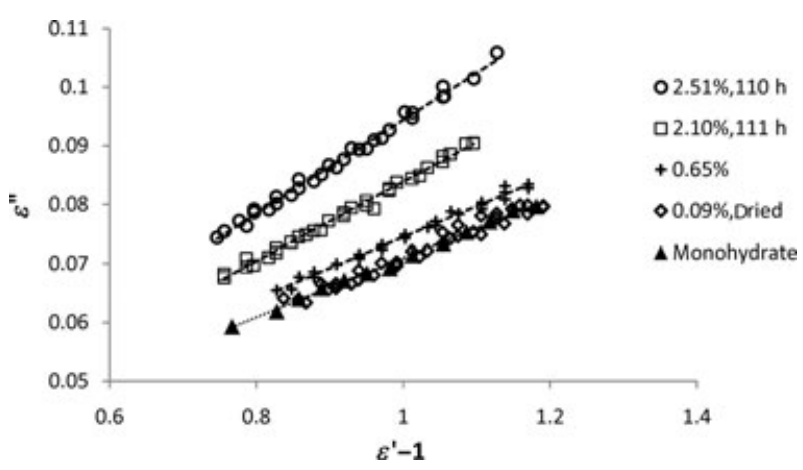

Figure 7. The relationship between $\varepsilon^{\prime \prime}$ and $\varepsilon^{\prime}-1$ for initially anhydrous lactose measured 4 days after addition of moisture with density varying $\left(f_{\mathrm{r}}=700-740 \mathrm{MHz}\right.$, nominally, $75^{\circ} \mathrm{F}$ ). 


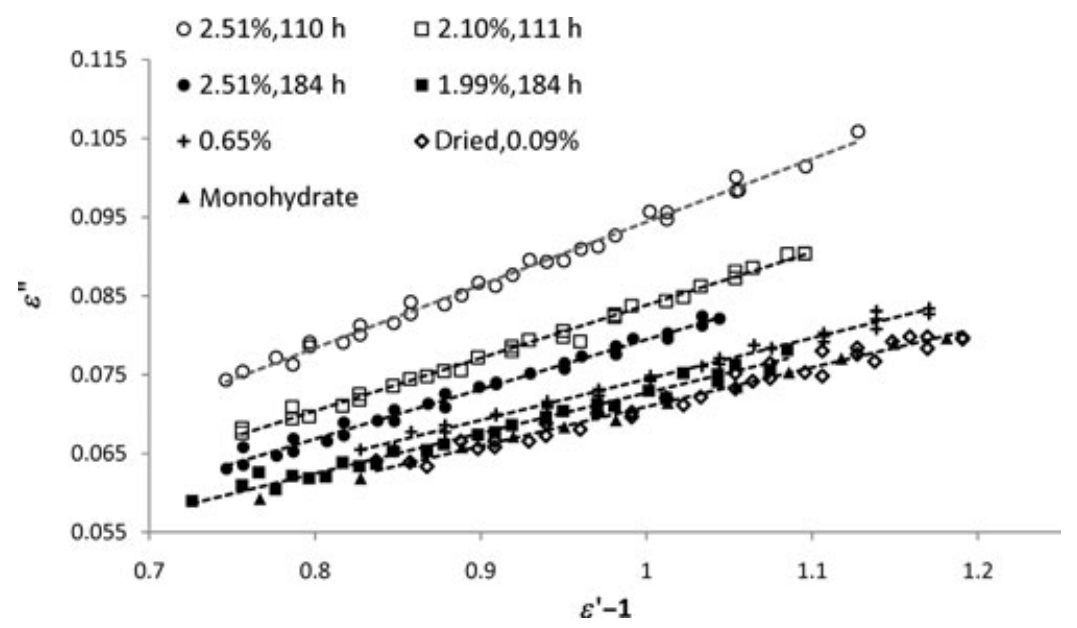

Figure 8. The relationship between $\varepsilon^{\prime \prime}$ and $\varepsilon^{\prime}-1$ for anhydrous lactose, 110- and 184-h samples with density varying $\left(f_{\mathrm{r}}=700-740 \mathrm{MHz}\right.$, nominally, $\left.75^{\circ} \mathrm{F}\right)$.

a conversion time of $184 \mathrm{~h}, 2.10 \% \mathrm{MC}$ at a conversion time of $111 \mathrm{~h}$, and $2.51 \% \mathrm{MC}$ at conversion times of 110 and $184 \mathrm{~h}$. The $\varepsilon^{\prime \prime}$ and $\varepsilon^{\prime}-1$ curve for the $\alpha$-lactose monohydrate without being heated or wetted was included again. The linear model parameter estimates are given in Table 3 for the data in Figure 8.

The $\varepsilon^{\prime \prime}$ and $\varepsilon^{\prime}-1$ curve for the $2.51 \%$ MC sample at a conversion time of $184 \mathrm{~h}$ was lower than the $\varepsilon^{\prime \prime}$ and $\varepsilon^{\prime}-1$ curve for the $2.10 \% \mathrm{MC}$ sample at a conversion time of $111 \mathrm{~h}$, and more unexpectedly, the $\varepsilon^{\prime \prime}$ and $\varepsilon^{\prime}-1$ curve for the $1.99 \% \mathrm{MC}$ curve at a conversion time of $184 \mathrm{~h}$ was lower than the anhydrous lactose taken out from the drum, prior to moisture addition. Thus, the physisorbed and "free" water is depleted as anhydrous lactose is converted to $\alpha$-lactose monohydrate. The percentage of the $\alpha$-lactose monohydrate in the samples at different conversion times was further confirmed using Raman spectroscopy, which will be discussed subsequently.
Although the anhydrous lactose is converted to $\alpha$ monohydrate lactose in the presence of the moisture, wetted $\alpha$-monohydrate lactose powder did not form any higher crystal hydrates as expected. The relation between $\varepsilon^{\prime \prime}$ and $\varepsilon^{\prime}-1$ measured at different times after adding water to the $\alpha$-lactose monohydrate powders (which contain average MCs of $6.04 \%$ and $6.70 \%$ ) are shown in Figure 9. Figure 9 shows an overlap of the curves for powders at the same moisture level but different conversion times, which means that unlike the physisorbed and "free" water in the anhydrous lactose powder, this physisorbed and "free" water does change the crystal structure of $\alpha$-lactose monohydrate. The slopes of the $\varepsilon^{\prime \prime}$ and $\varepsilon^{\prime}-1$ curve for the pure $\alpha$-monohydrate lactose ( $\mathrm{MC}=5.25 \%$, Fig. 8 and Table 3 ) and the wetted $\alpha$-monohydrate lactose ( $\mathrm{MC}=$ $6.70 \pm 0.15 \%$, Fig. 9) are 0.05 and 0.10 , respectively. Thus, the resonator sensor detected the addition of free water to the powder.

Table 2. The Fitting Equations and Bulk Density Range of the Curves in Figure 7

\begin{tabular}{llc}
\hline Name of Equation & \multicolumn{1}{c}{ Fitting Equation } & Bulk Density Range \\
\hline$\bigcirc$ MC $2.51 \%, 110 \mathrm{~h}$ & $y=0.08 x+0.0144, R^{2}=0.9924$ & $0.50-0.76 \mathrm{~g} / \mathrm{cm}^{3}$ \\
$\square$ MC $2.10 \%, 111 \mathrm{~h}$ & $y=0.0671 x+0.0168, R^{2}=0.9934$ & $0.51-0.77 \mathrm{~g} / \mathrm{cm}^{3}$ \\
+ MC 0.65\% & $y=0.0521 x+0.0223, R^{2}=0.9907$ & $0.57-0.83 \mathrm{~g} / \mathrm{cm}^{3}$ \\
$\diamond$ MC 0.09\%, dried & $y=0.0498 x+0.0211, R^{2}=0.9704$ & $0.59-0.84 \mathrm{~g} / \mathrm{cm}^{3}$ \\
$\Delta$-lactose monohydrate, MC 5.25\% & $y=0.0501 x+0.0208, R^{2}=0.9967$ & $0.54-0.87 \mathrm{~g} / \mathrm{cm}^{3}$ \\
\hline
\end{tabular}

Table 3. The Fitting Equations and Bulk Density Range of the Curves in Figure 8

\begin{tabular}{llc}
\hline Name of Equation & \multicolumn{1}{c}{ Fitting Equation } & Bulk Density Range \\
\hline$\bigcirc$ MC $2.51 \%, 110 \mathrm{~h}$ & $y=0.08 x+0.0144, R^{2}=0.9924$ & $0.50-0.76 \mathrm{~g} / \mathrm{cm}^{3}$ \\
$\square$ MC $2.10 \%, 111 \mathrm{~h}$ & $y=0.0671 x+0.0168, R^{2}=0.9934$ & $0.51-0.77 \mathrm{~g} / \mathrm{cm}^{3}$ \\
$\bigcirc$ MC $2.51 \%, 184 \mathrm{~h}$ & $y=0.0631 x-0.0468, R^{2}=0.9876$ & $0.51-0.75 \mathrm{~g} / \mathrm{cm}^{3}$ \\
$\mathbf{\square}$ MC $1.99 \%, 184 \mathrm{~h}$ & $y=0.0513 x-0.0298, R^{2}=0.9822$ & $0.52-0.79 \mathrm{~g} / \mathrm{cm}^{3}$ \\
+ MC 0.65\% & $y=0.0521 x+0.0223, R^{2}=0.9907$ & $0.57-0.83 \mathrm{~g} / \mathrm{cm}^{3}$ \\
$\diamond$ MC 0.09\%, dried & $y=0.0498 x+0.0211, R^{2}=0.9704$ & $0.59-0.84 \mathrm{~g} / \mathrm{cm}^{3}$ \\
$\boldsymbol{\Delta} \alpha$ - lactose monohydrate, MC 5.25\% & $y=0.0501 x+0.0208, R^{2}=0.9967$ & $0.54-0.87 \mathrm{~g} / \mathrm{cm}^{3}$ \\
\hline
\end{tabular}




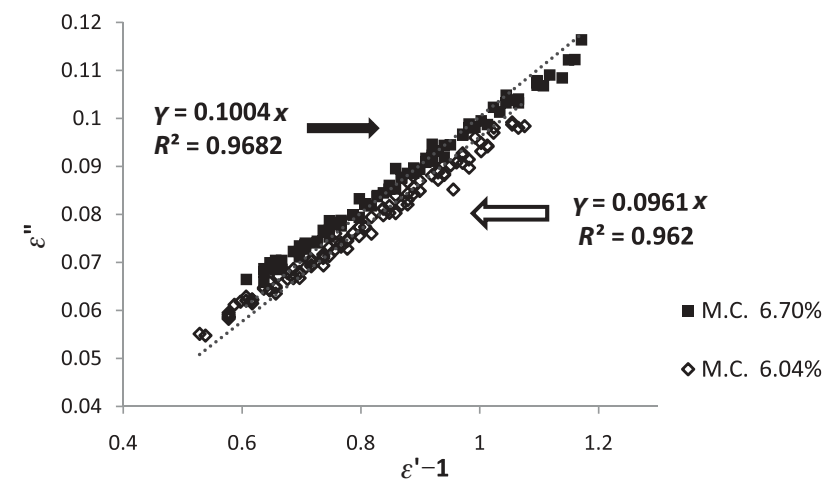

Figure 9. The relationship between $\varepsilon^{\prime \prime}$ and $\varepsilon^{\prime}-1$ for $\alpha$ lactose monohydrate measured different days after the addition of moisture (MC $6.70 \pm 0.15 \%$ and $\mathrm{MC} 6.04 \pm$ $0.19 \%$, with $f_{\mathrm{r}}=700-740 \mathrm{MHz}$, nominally, $\left.75^{\circ} \mathrm{F}\right)$; bulk densities range: $\mathrm{MC}$ at $6.70 \%: 0.36-0.73 \mathrm{~g} / \mathrm{cm}^{3} ; \mathrm{MC}$ at $6.04 \%$ : $0.37-0.72 \mathrm{~g} / \mathrm{cm}^{3}$.

The MCs of samples from different locations inside this $\alpha$-lactose monohydrate powders with average MCs of $6.04 \%$ and $6.70 \%$ are also given in Tables 4 and 5 . The $\alpha$-lactose monohydrate contains $5.25 \%$ of crystallographic water prior to additional water addition. The Raman spectra of wetted $\alpha$-lactose monohydrate powders for conversion times up to $190.3 \mathrm{~h}$ showed only $\alpha$-lactose monohydrate existing in the sample.

\section{Lactose Crystal Form Analysis Using Raman Spectroscopy}

The Raman spectra of anhydrous lactose and $\alpha$ lactose monohydrate are shown in Figure 10. Peaks at Raman shifts of $414 \mathrm{~cm}^{-1}$ and $398 \mathrm{~cm}^{-1}$ were selected for quantitative determination of anhydrous and $\alpha$ monohydrate, respectively, due to minimal spectral interference at these wavenumber shifts. A calibration curve was constructed by plotting this peak ratio against the experimental molar ratio of anhydrous lactose/ $\alpha$-lactose monohydrate. The resultant calibration curve, shown in Figure 11, was then used to quantify the amount of $\alpha$-lactose monohydrate formed from the wetted anhydrous lactose.

On the basis of the calibration curve above, the percentage of $\alpha$-lactose monohydrate in the wetted anhydrous lactose samples was determined and results are shown in Figure 12. The conversion time and the average $\mathrm{MC}$ are also displayed.

In Figure 12, the conversion time is represented on the horizontal axis in days instead of hours for convenience. The percentage of conversion to $\alpha$-lactose monohydrate increased with time and the amount of water added to the initial anhydrous lactose powder. The comparison in Raman spectra between the 111and 184-h samples is shown in Figure 13. The 111$h$ curve has been normalized such that its intensity at a wavenumber shift of $414 \mathrm{~cm}^{-1}$ is the same as the 184-h curve at the same wavenumber shift. This normalization allows for comparison of the $\alpha$-lactose monohydrate peak intensity of the 111- and 184-h samples at a wavenumber shift of $398 \mathrm{~cm}^{-1}$. The 184-h curve has a more intense peak at $398 \mathrm{~cm}^{-1}$; therefore, the percentage of the $\alpha$-lactose monohydrate is higher, confirming the formation of the hydrate form over time in the wetted anhydrous lactose sample.

\section{Effect of Moisture on the Dielectric Properties of MCC}

Microcrystalline cellulose does not form hydrates when the powder is wetted; however, due to the presence of disordered regions, added moisture can be physically absorbed into the bulk of MCC as well as being adsorbed at the surface. After addition of water to the MCC powder, samples were taken from nine different locations in the powder. The MCs in the samples are reported in Table 6 and were measured by the LOD method on small portions of the samples. The average MC of the MCC powder is about $5.84 \%$.

Table 4. Moisture Content Measured in Different Locations for One Wetted $\alpha$-Lactose Monohydrate Sample Preparation, MC 6.04\%

\begin{tabular}{|c|c|c|c|c|c|c|c|c|c|}
\hline & $67-1$ & $67-2$ & $67-3$ & $115-1$ & $115-2$ & $115-3$ & $190-1$ & $190-2$ & $190-2$ \\
\hline $\mathrm{MC}$ & $5.95 \%$ & $6.10 \%$ & $6.23 \%$ & $6.06 \%$ & $6.21 \%$ & $6.27 \%$ & $6.0 \%$ & $5.74 \%$ & $5.77 \%$ \\
\hline $\begin{array}{l}m_{\mathrm{w}}+m_{\mathrm{p}} \\
\quad \text { used (g) }\end{array}$ & 313 & 311 & 317 & 311 & 319 & 325 & 314 & 316 & 320 \\
\hline $\mathrm{MC}$ & \multicolumn{3}{|c|}{ Average of 67 -h bag: $6.09 \%$ SD: $0.14 \%$} & \multicolumn{3}{|c|}{ Average of 110 -h bag: $6.18 \%$ SD: $0.11 \%$} & \multicolumn{3}{|c|}{ Average of 184 -h bag: $5.84 \%$ SD: $0.14 \%$} \\
\hline
\end{tabular}

Average of the entire original bag: $6.04 \%$.

Table 5. Moisture Content Measured in Different Locations for One Wetted $\alpha$-Lactose Monohydrate Sample Preparation, MC 6.70\%

\begin{tabular}{|c|c|c|c|c|c|c|c|c|c|}
\hline & $67-1$ & $67-2$ & $67-3$ & $114-1$ & $114-2$ & $114-3$ & $190-1$ & $190-2$ & $190-3$ \\
\hline $\mathrm{MC}$ & $6.58 \%$ & $6.73 \%$ & $6.78 \%$ & $6.57 \%$ & $6.97 \%$ & $6.43 \%$ & $6.71 \%$ & $6.77 \%$ & $6.75 \%$ \\
\hline $\begin{array}{c}m_{\mathrm{w}}+m_{\mathrm{p}} \\
\quad \text { used }(\mathrm{g})\end{array}$ & 304 & 305 & 309 & 318 & 327 & 327 & 303 & 307 & 297 \\
\hline $\mathrm{MC}$ & Average & bag: 6 . & SD: $0.10 \%$ & Average 0 & h bag: 6 & SD: $0.28 \%$ & \multicolumn{3}{|c|}{ Average of 184 -h bag: $6.74 \%$ SD: $0.03 \%$} \\
\hline
\end{tabular}

Average of the entire original bag: $6.70 \%$. 


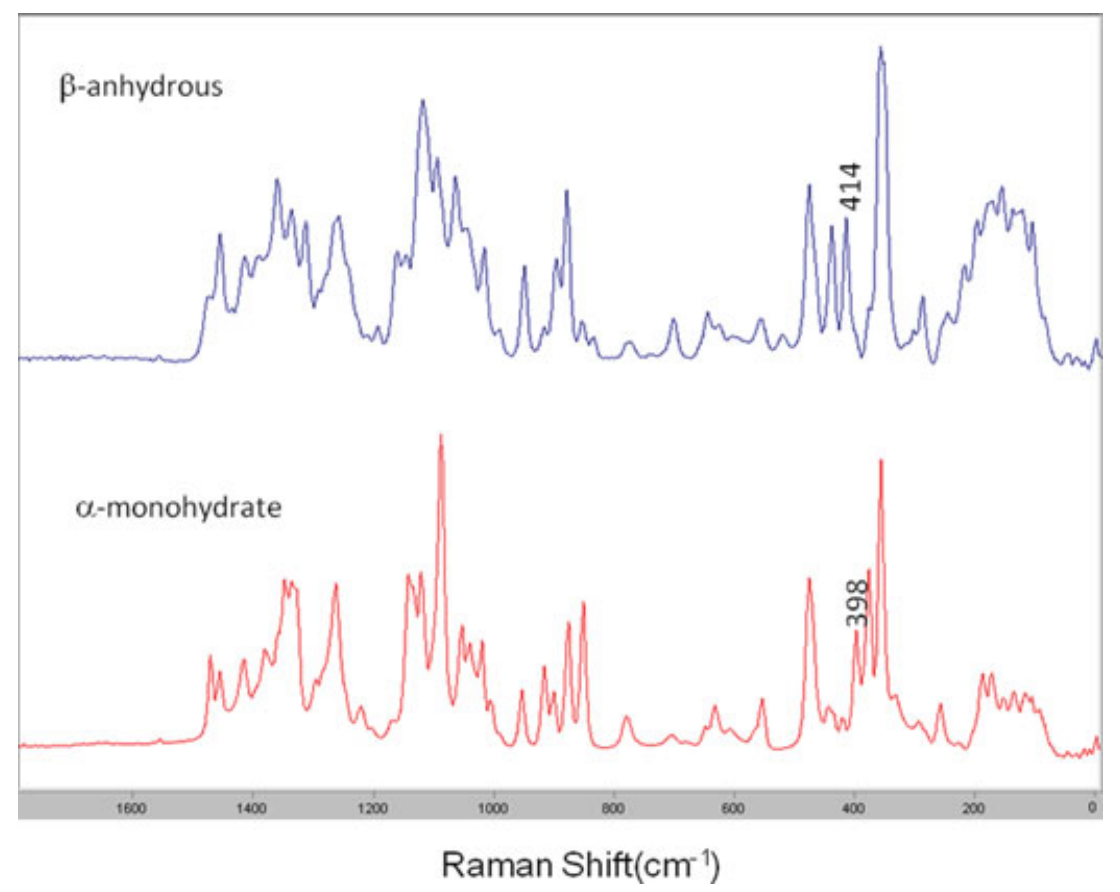

Figure 10. Raman spectra of anydrous lactose and $\alpha$-lactose monohydrate.

The dielectric properties of wetted anhydrous lactose with an MC of $2.50 \%$ were compared with the $5.84 \%$ MC MCC powder in both Figures 14 and 15. The dielectric properties of wetted MCC powders were taken at various times after water was added to the powder. These figures also show a comparison of the temporal effect of moisture on the dielectric properties of the MCC and anhydrous lactose powders. The figures reveal a lesser temporal effect of the moisture on the dielectric properties of the MCC powder in comparison with the anhydrous lactose powder.

Figure 16 is a plot of $\varepsilon^{\prime \prime}$ versus $\varepsilon^{\prime}-1$ that is measured at different times after addition of water to MCC powder. The curves are very close to each other indicating that the physisorbed water in MCC is easily detected by the resonator sensor and is thus highly mobile, unlike the crystallographic water in lactose monohydrate. The MC results of Figure 16 are given in Table 6.

The relationship between $\varepsilon^{\prime \prime}$ and $\varepsilon^{\prime}-1$ for MCC of different MCs is also plotted in Figure 17. MCC has about $4.65 \% \mathrm{MC}$ as received from the manufacturer. Although the dashed lines represent different bulk densities at constant MC, the solid lines are the fitting curves of the data points from different moisture levels having the same bulk densities. Note that the dielectric properties increase with increasing density and MC.

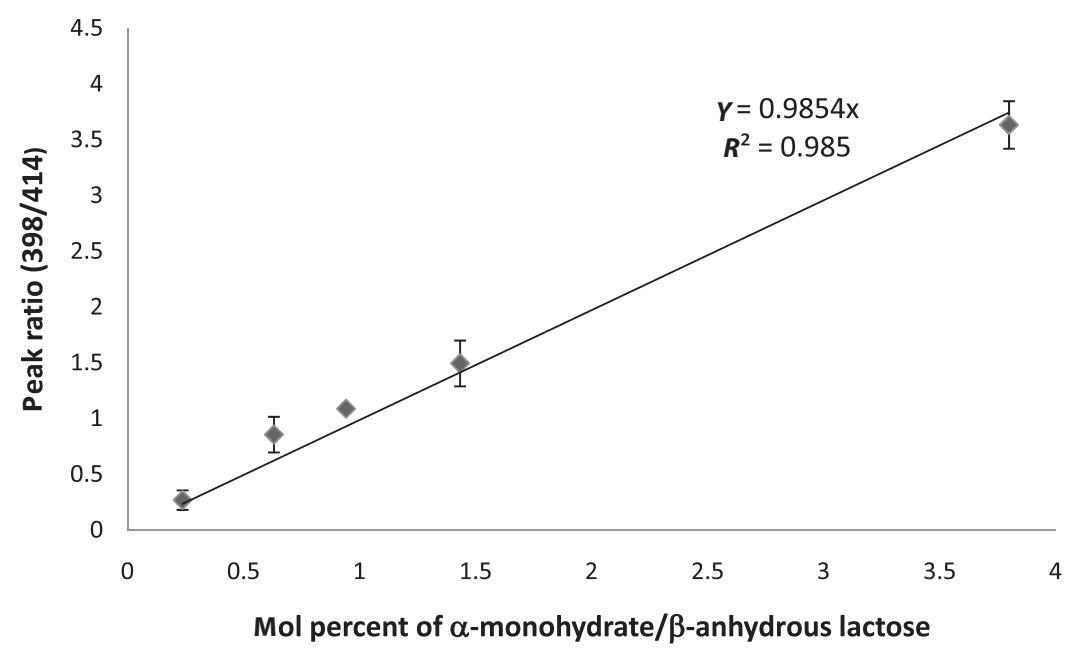

Figure 11. Calibration curve for anhydrous lactose/ $\alpha$-lactose monohydrate. 


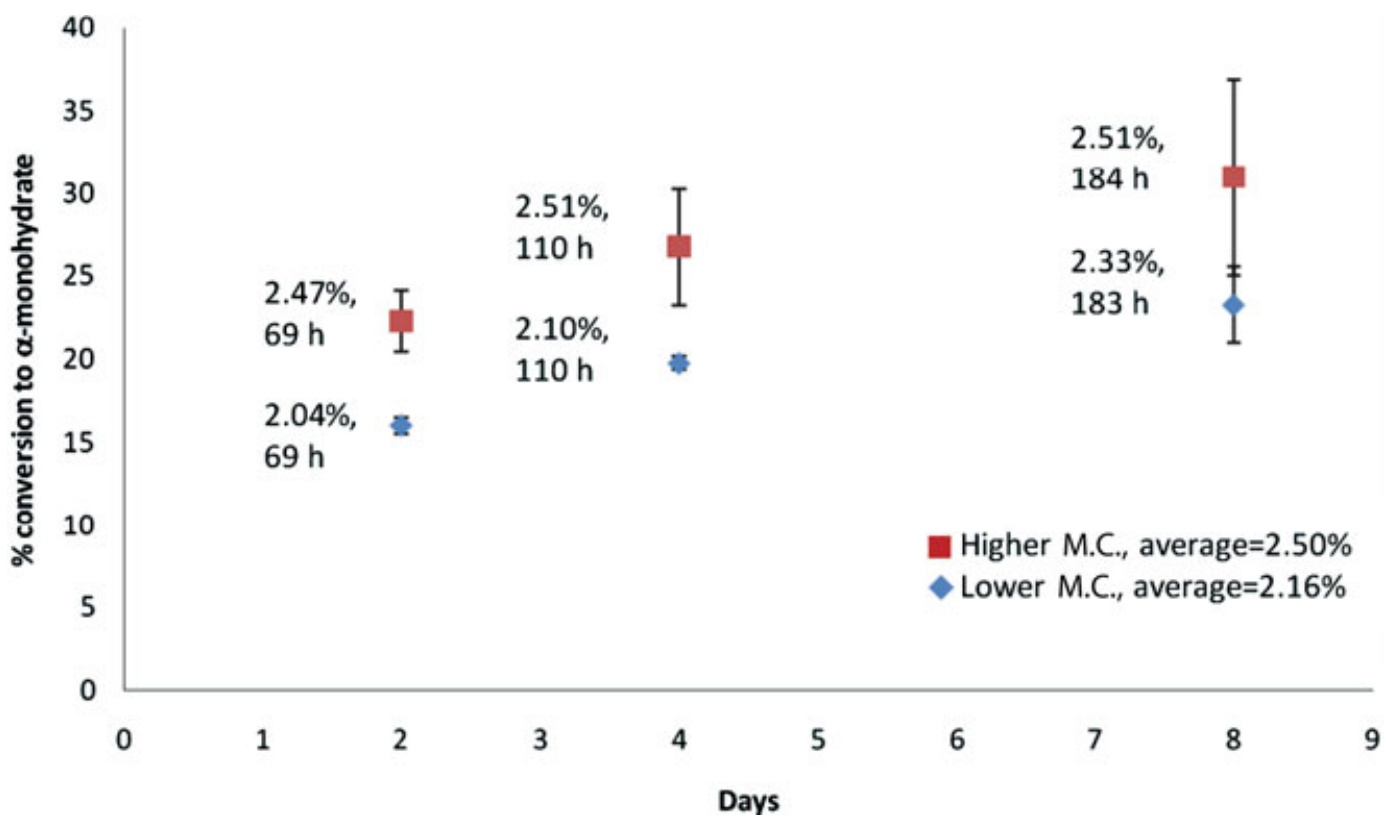

Figure 12. The percentage of conversion into $\alpha$-monohydrate of samples with two different moisture content levels at different conversion times.

By using the interpolation from this plot of $\varepsilon^{\prime \prime}$ and $\varepsilon^{\prime}-1$ curves, bulk densities and MC of unknown samples can be obtained. The linear model parameter estimates and the range of the bulk densities for each curve are given in Table 7 for the data in Figure 17.

\section{DISCUSSION}

The dielectric properties of MCC and the anhydrous lactose exhibit different behaviors after the addition of water to the powders; for the former system, water is absorbed into disordered regions, whereas in the latter system, addition of water results changes to the crystal structures. For both powders, the MC should be monitored carefully and controlled during storage before they are tabletted. For example, the compaction properties of MCC are known to be highly dependent on the MC. MCC is a powder which absorbs water into its disordered regions in addition to surface adsorption. The absorbed moisture acts as a plasticizer, changing its compaction behavior. An increase in the MC will lower the yield strength of the MCC and make it more deformable. ${ }^{20}$ It has also been suggested that the rapid moisture sorption by MCC can be used to protect other excipients from moisture uptake. ${ }^{21}$ Anhydrous lactose powders do not absorb water as fast as MCC powders; however, anhydrous lactose is converted to the $\alpha$-lactose monohydrate

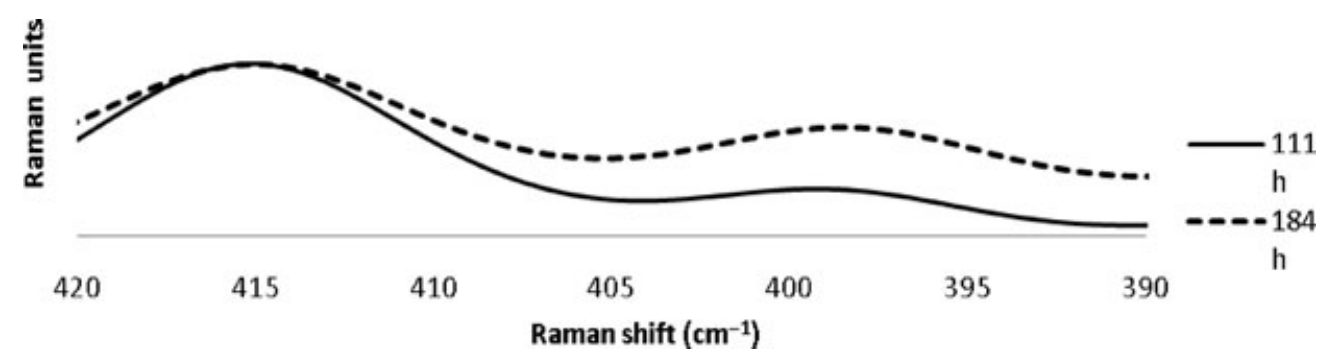

Figure 13. Raman spectra of the 2.51\%, 111-h sample and 2.51\%, 184-h sample.

Table 6. Moisture Content Measured in Different Locations of One Wetted MCC Sample

\begin{tabular}{|c|c|c|c|c|c|c|c|c|c|}
\hline & $60-1$ & $60-2$ & $60-3$ & $105-1$ & $105-2$ & $105-3$ & $207-1$ & $207-2$ & $207-3$ \\
\hline $\mathrm{MC}$ & $5.82 \%$ & $5.79 \%$ & $5.58 \%$ & $5.99 \%$ & $5.96 \%$ & $5.84 \%$ & $5.87 \%$ & $5.88 \%$ & $5.85 \%$ \\
\hline $\begin{array}{l}m_{\mathrm{w}}+m_{\mathrm{p}} \\
\quad \text { used (g) }\end{array}$ & 244 & 244 & 247 & 239 & 241 & 245 & 241 & 242 & 251 \\
\hline $\mathrm{MC}$ & Average & bag: 5 . & SD: $0.13 \%$ & Average 0 & h bag: 5 & SD: $0.08 \%$ & Average o & h bag: 5 . & SD: $0.02 \%$ \\
\hline
\end{tabular}

\footnotetext{
Average of the entire original bag: $5.84 \%$.
} 


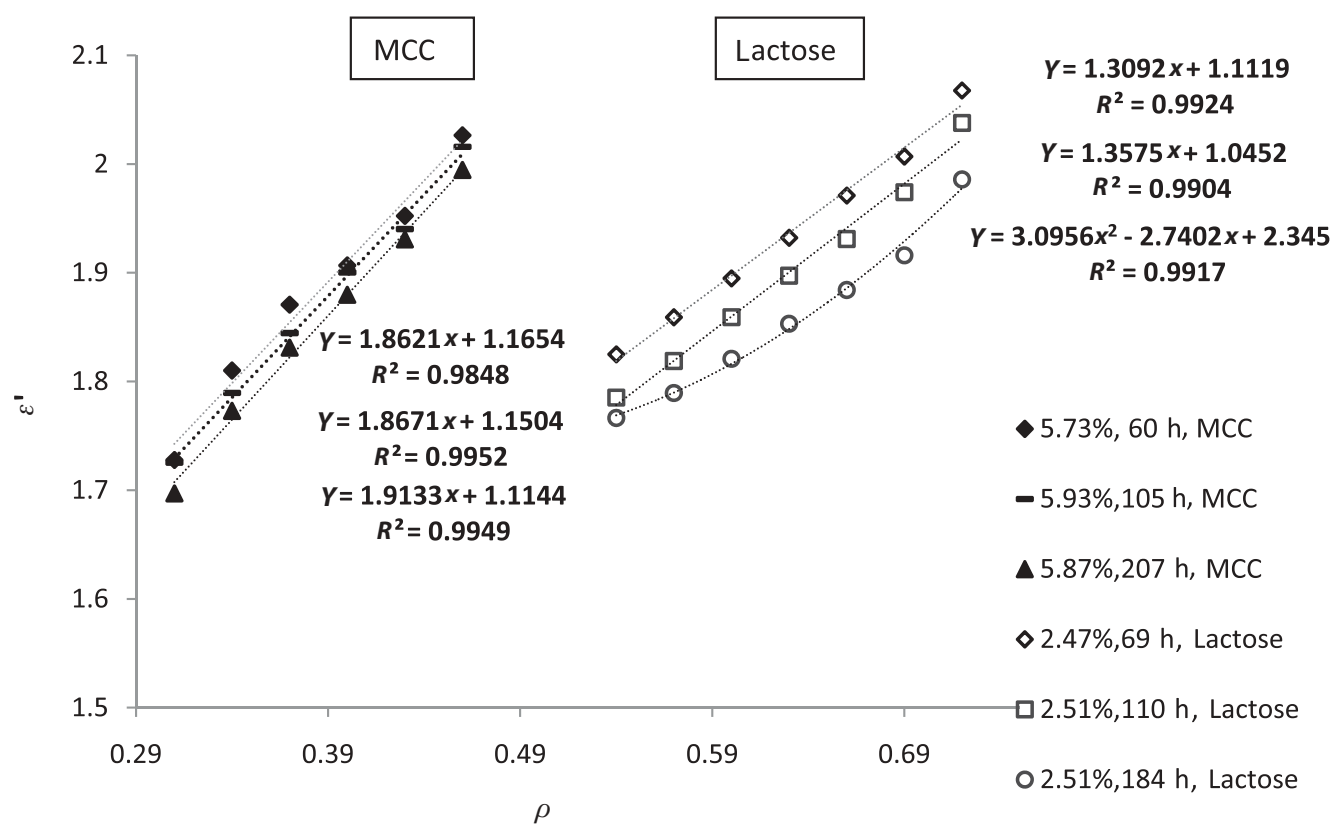

Figure 14. The comparison of $\varepsilon^{\prime}$ and $r$ relationships for different measurement times for MCC with $5.48 \% \mathrm{MC}$ and anhydrous lactose with $2.50 \% \mathrm{MC}$.

form in the presence of moisture, which in turn affects the compressibility of the powder and the strength of the downstream product. ${ }^{18,22}$ The conversion of anhydrous lactose to $\alpha$-lactose monohydrate with the consumption of the physisorbed and "free" water makes control of the uniformity of the physical properties of entire bulk sample difficult due to the variations in the relative amounts of anhydrous lactose and $\alpha$ lactose monohydrate.
The conversion of wetted anhydrous lactose powder to $\alpha$-lactose monohydrate resulted in a downward shift in the $\varepsilon^{\prime \prime}$ versus $\varepsilon^{\prime}-1$ curve over time. This showed the expected higher sensitivity of the microwave-based sensor to physisorbed and "free" water in the powder where the physisorbed and "free" water was depleted as the $\alpha$-lactose monohydrate was formed. The data showed a convergence of the $\varepsilon^{\prime \prime}$ versus $\varepsilon^{\prime}-1$ curves for the wetted anhydrous lactose

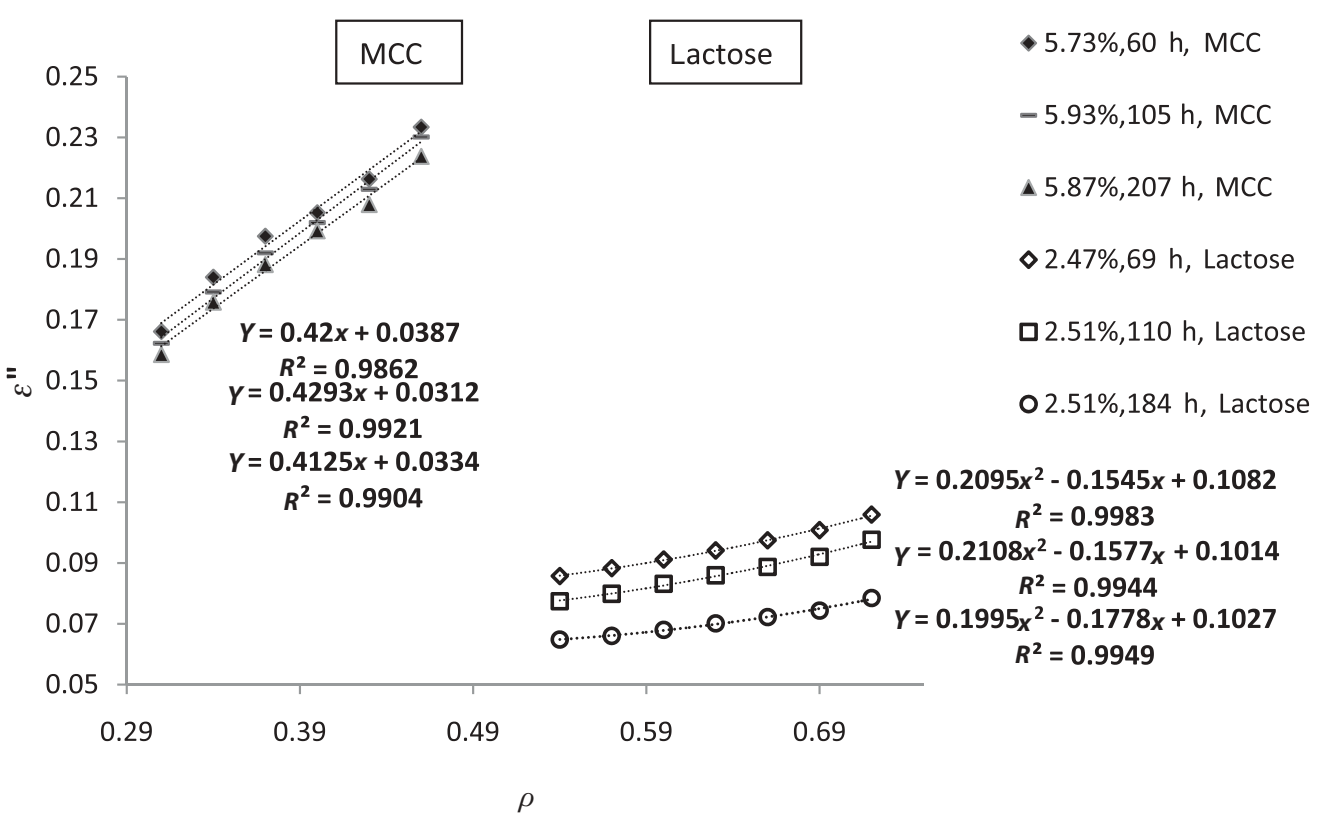

Figure 15. The comparison of $\varepsilon^{\prime \prime}$ and $r$ relationships for different measurement times for MCC with $5.84 \% \mathrm{MC}$ and anhydrous lactose with $2.50 \% \mathrm{MC}$. 


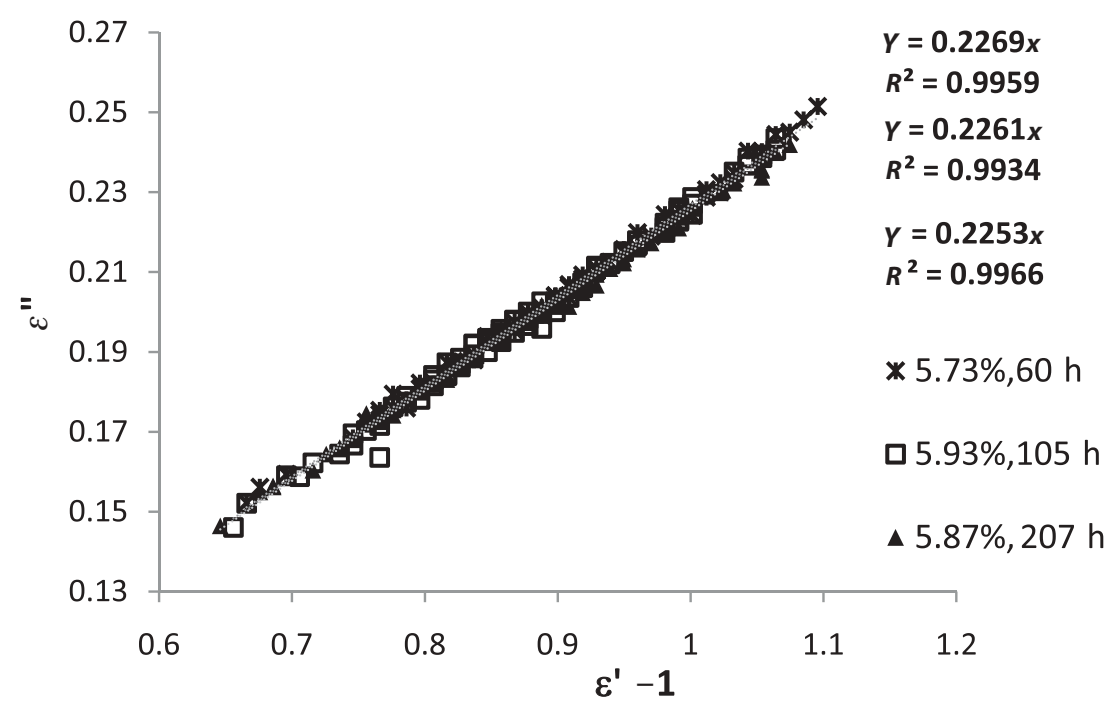

Figure 16. The relationship between $\varepsilon^{\prime \prime}$ and $\varepsilon^{\prime}-1$ for MCC with MC of $5.84 \%$ at different measurement times, with density varying.

powders as the conversion time increases to $184 \mathrm{~h}$, thus showing a depletion of the physisorbed and "free" water as it interacted with the anhydrous lactose powder to form the $\alpha$-lactose monohydrate. There was not a temporal downward shift in the $\varepsilon^{\prime \prime}$ versus $\varepsilon^{\prime}-1$ curve for the wetted MCC powder because MCC absorbed the added moisture immediately and did not undergo any discernable structural change with time. Thus, the physical state of water in the sample did not change over time in wetted MCC.

Raman spectroscopy was used to monitor the formation of $\alpha$-lactose monohydrate. The spectroscopic results in Figure 12 were used to estimate the amount of water that is still in physisorbed or free state in the

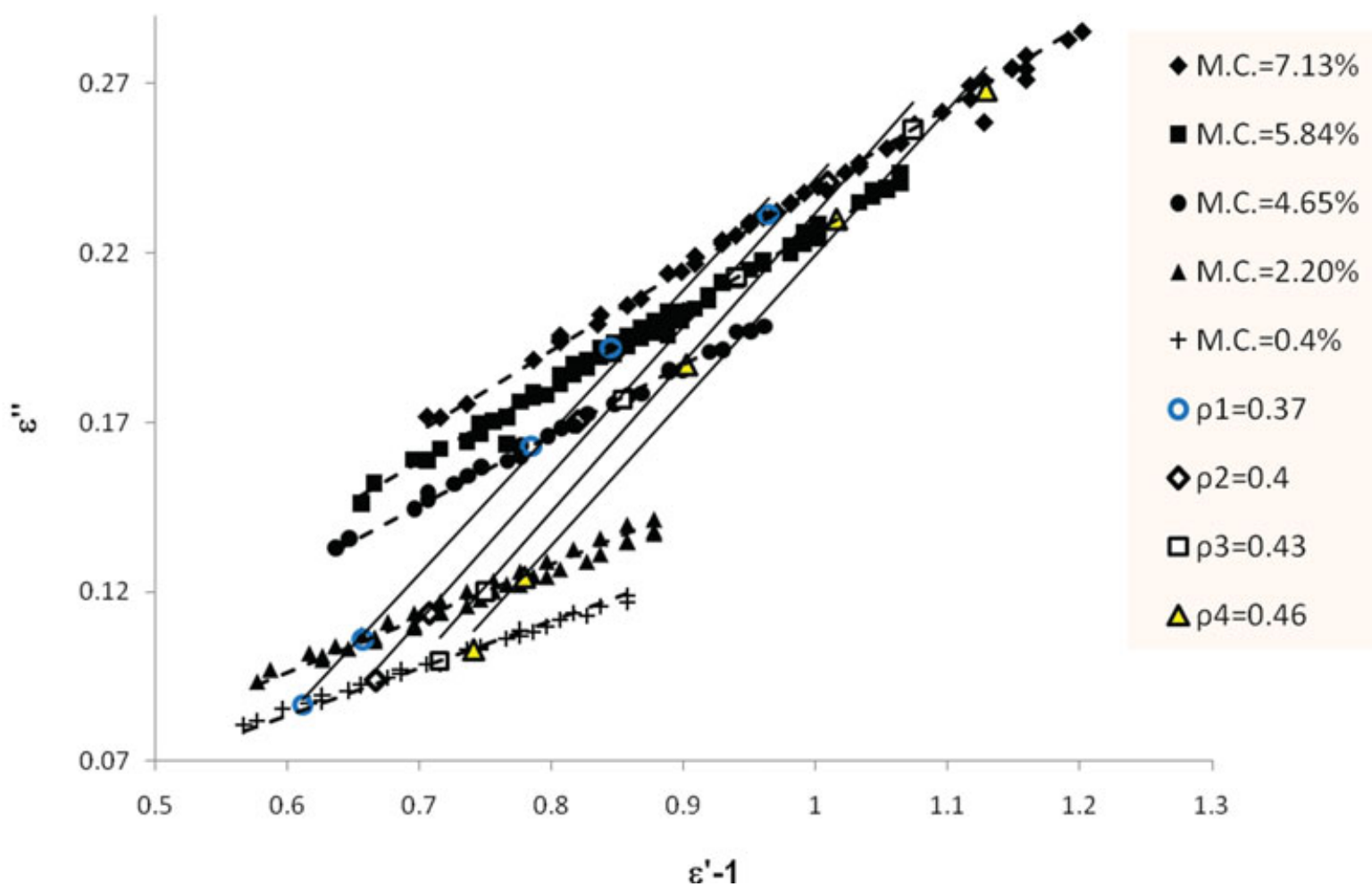

Figure 17. The relationship between $\varepsilon^{\prime \prime}$ and $\varepsilon^{\prime}-1$ at different moisture contents with density varying for MCC. 
Table 7. The Fitting Equations and the Bulk Density Range for the Curves in Figure 17

\begin{tabular}{llc}
\hline Name of Equation & \multicolumn{1}{c}{ Fitting Equation } & Bulk Density Range \\
\hline MC $7.13 \pm 0.07 \%$ & $y=0.239 x, R^{2}=0.9947$ & $0.28-0.48 \mathrm{~g} / \mathrm{cm}^{3}$ \\
MC $5.84 \pm 0.02 \%$ & $y=0.2261 x, R^{2}=0.9934$ & $0.29-0.48 \mathrm{~g} / \mathrm{cm}^{3}$ \\
$\bigcirc$ MC $4.65 \pm 0.13 \%$ & $y=0.2078 x, R^{2}=0.9963$ & $0.30-0.49 \mathrm{~g} / \mathrm{cm}^{3}$ \\
MC $2.20 \pm 0.04 \%$ & $y=0.16 x, R^{2}=0.9738$ & $0.33-0.53 \mathrm{~g} / \mathrm{cm}^{3}$ \\
+ MC $0.4 \pm 0.11 \%$ & $y=0.1392 x, R^{2}=0.9973$ & $0.35-0.56 \mathrm{~g} / \mathrm{cm}^{3}$ \\
$\bigcirc \rho 1=0.37$ & $y=0.4196 x-0.1683, R^{2}=0.9953$ & \\
$\diamond \rho 2=0.40$ & $y=0.4351 x-0.1931, R^{2}=0.9937$ & \\
$\square \rho 3=0.43$ & $y=0.4407 x-0.2087, R^{2}=0.9849$ & \\
$\Delta \rho 4=0.46$ & $y=0.4285 x-0.209, R^{2}=0.9907$ & \\
\hline
\end{tabular}

wetted anhydrous lactose as the anhydrous lactose was converted to $\alpha$-lactose monohydrate. Estimates of the percent conversion of anhydrous lactose to $\alpha$ lactose monohydrate are summarized in Table 8.

The temporal amount of the physisorbed and "free" water in the wetted powder with an initial $\mathrm{MC}=$ $2.50 \%$ was calculated by subtracting the amount of water required to convert anhydrous lactose to $\alpha$ lactose monohydrate from the amount of water initially added to the powder. It should be noted that the $\mathrm{MC}$ of 2.5\% represents the water added to the powder plus the amount of water $(0.65 \%)$ already in the purchased powder. The estimated physisorbed and "free" water contents with the errors for the wetted anhydrous lactose powder after 2,4 , and 8 days are given in Table 9. The percentage of $\alpha$-lactose monohydrate inside the anhydrous lactose before the addition of water was negligible (also confirmed from the Raman spectra). The physisorbed and "free" water content in the wetted lactose sample decreases with time, which is in qualitative agreement with the downward shift in the $\varepsilon^{\prime \prime}$ versus $\varepsilon^{\prime}-1$ curve for the wetted anhydrous lactose samples.

Combining Figure 6 and Table 9, we can see that the difference in noncrystallographically bound water (i.e., "free" water or physisorbed water) between the top and bottom curve in Figure 6 is about $0.43 \pm 0.2 \%$ MC, demonstrating exceptional sensitivity to free water with the microwave sensor. This is because a small amount of free water can have a profound effect on $\varepsilon^{\prime \prime}$ and $\varepsilon^{\prime}$. The same amount of the crystallographic water will have a much lower effect. Stated another way, microwave sensing will be less sensitive to water incorporated into the crystal lattice as compared with free or physisorbed water as is shown in Figure 6.

Table 8. Percent Anhydrous Lactose Converted to $\alpha$-Lactose Monohydrate

\begin{tabular}{lcclccc}
\hline & \multicolumn{2}{c}{ Initial $\mathrm{MC}=2.0-2.3 \%$} & & \multicolumn{2}{c}{ Initial $\mathrm{MC}=2.5 \%}$. \\
\cline { 2 - 3 } \cline { 5 - 6 } & $\%$ converted & $\mathrm{SD}$ & & $\%$ converted & $\mathrm{SD}$ \\
\hline 2 days & 16.017 & 0.518 & & 22.286 & 1.874 \\
4 days & 19.763 & 0.422 & & 26.770 & 3.492 \\
8 days & 23.289 & 2.266 & & 30.989 & 5.917 \\
\hline
\end{tabular}

The $\varepsilon^{\prime \prime}$ versus $\varepsilon^{\prime}-1$ curves for the wetted $\alpha$ lactose monohydrate powders did not show a downward shift, which indicates no temporal change in the physisorbed and "free" water content in the powder, which is similar to the interaction between MCC and the moisture. The MCC and $\alpha$-lactose monohydrate powders do not show changes in the chemical structure due to hydration after being wetted; therefore, the microwave-based sensor measurement can be used for measuring the physisorbed and/or "free" water content of these two powders. The difference in the dielectric response between the bound water and the physisorbed and free water was also described in previous studies ${ }^{12,23}$ that below the critical MC where we deal primarily with bound water, the change in the dielectric loss with the increasing moisture will be relatively small. In our research, using the linear model parameter estimated from the MCC data shown in Figure 17, the relation between $\mathrm{MC}$ and the ratio, $\varepsilon^{\prime \prime}$ I $\varepsilon^{\prime}-1$ (or slopes of the $\varepsilon^{\prime \prime}$ versus $\varepsilon^{\prime}-1$ ) instead of $\varepsilon^{\prime \prime}$, was obtained as shown in Figure 18. The MC increases linearly with $\varepsilon^{\prime \prime} / \varepsilon^{\prime}-1$ and relation is independent of the bulk density of the powder for MCC. The anhydrous lactose and $\alpha$-lactose monohydrate were not discussed here due to the existence of the bound water after being wetted. Previous studies also tried to relate a density-independent function of $\varepsilon^{\prime \prime}$ and $\varepsilon^{\prime}$ to the MC for starch $^{12}$; however, their results seemed to be linear only within a certain range of the MC, and the effect of the water at different states in the powder on the dielectric properties was not addressed clearly. Figure 17 in this paper shows that $\varepsilon^{\prime \prime} / \varepsilon^{\prime}-1$ is a proper choice of this "density-independent function" for MCC in which the water stays most likely as free or physisorbed water, and as shown in Figure 18,

Table 9. The Physisorbed and "Free" Water Calculation for MC 2.50\% Wetted Anhydrous Lactose

\begin{tabular}{lccc}
\hline & $\begin{array}{c}\text { Anhydrous } \\
\text { Lactose }\end{array}$ & $\begin{array}{c}\alpha \text {-lactose } \\
\text { Monohydrate }\end{array}$ & Free Water \\
\hline Initial amount & 97.5 & 0 & 1.85 \\
After 2 days & $76.62 \pm 0.89$ & $21.97 \pm 0.93$ & $0.75 \pm 0.05$ \\
After 4 days & $72.37 \pm 1.66$ & $26.45 \pm 1.75$ & $0.53 \pm 0.09$ \\
After 8 days & $68.34 \pm 2.83$ & $30.69 \pm 2.98$ & $0.32 \pm 0.15$ \\
\hline \multicolumn{2}{c}{ Unit: g/100 g of powder. } & &
\end{tabular}




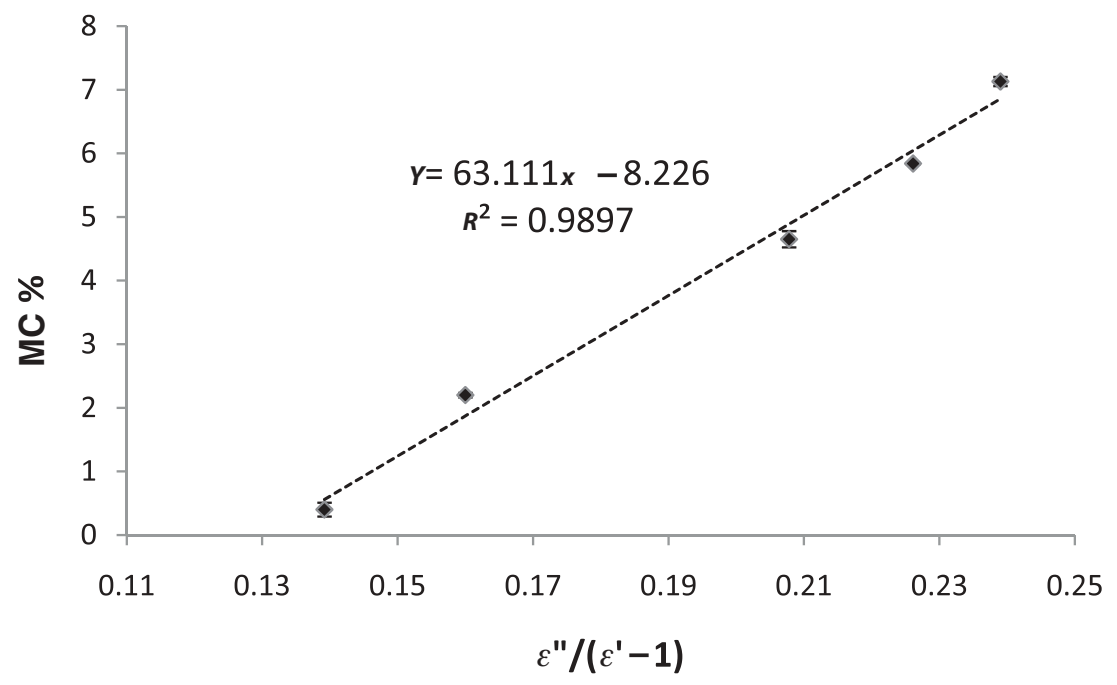

Figure 18. The relationship between moisture content and $\varepsilon^{\prime \prime} / \varepsilon^{\prime}-1$ for MCC.

$\varepsilon^{\prime \prime} / \varepsilon^{\prime}-1$ indeed shows a linear relation versus the MC, which provides a simple tool for the MC estimate for MCC samples where the MC is unknown. A future manuscript will provide a more thorough analysis on the use of graphs of the $\varepsilon^{\prime \prime}$ versus $\varepsilon^{\prime}-1$ curve for the simultaneous measurement of the bulk density and $\mathrm{MC}$ of pharmaceutical powders.

\section{CONCLUSION}

A reduction of the physisorbed and "free" water content in wetted anhydrous lactose was observed using a microwave resonator sensor. Subsequently, Raman spectroscopy measurements showed the temporal conversion of anhydrous lactose to $\alpha$-lactose monohydrate powders in the wetted anhydrous lactose powder. Graphs of $\varepsilon^{\prime \prime}$ versus $\varepsilon^{\prime}-1$ curve were constructed at a particular conversion time for wetted anhydrous lactose. Such graphs were also constructed for wetted MCC powder, which was time invariant. The graphs of $\varepsilon^{\prime \prime}$ versus $\varepsilon^{\prime}-1$ curve show the effect of both the MC and bulk density on the complex dielectric properties of the powders. Although each $\varepsilon^{\prime \prime}$ versus $\varepsilon^{\prime}-1$ curve was generated at constant MC, the bulk density of the powder was increased to generate each curve. This research is important in the development of inline techniques for the simultaneous measurement of MC and bulk density of pharmaceutical powders.

\section{ACKNOWLEDGMENTS}

The authors thank the National Science Foundation Engineering Research Center for Structured Organic Particulate Systems (NSF ERC-SOPS) (EEC0540855) for financial support.

\section{REFERENCES}

1. Zografi G, Kontny MJ, Yan AYS, Brenner GS. 1983. Surface area and water vapor sorption of macrocrystalline cellulose. Int J Pharm 18:99-116.

2. Garr JSM, Rubinstein MH. 1991. Compaction properties of a cellulose-lactose direct-compression excipient. Pharm Technol Int 3:24-27.

3. Earl WL, Parrish FW. 1983. A cross-polarization magic-angle sample spinning NMR study of several crystal forms of lactose. Carbohydr Res 115:23-32.

4. Nelson SO, Trabelsi S, Kraszewski WA. 1998. Advances in sensing grain moisture content by microwave measurements. Vol. 41. St.Joseph, Michigan: American Society of Agricultural Engineers.

5. Nyfors E. 2000. Industrial microwave sensors-A review. Subsurface Sensing Tech Appl 1:23-43.

6. Kraszewski AW. 1996. Microwave aquametry-electromagnetic wave interaction with water-containing materials, IEEE Press, New York.

7. Baltes H, Göpel W, Hesse J, guest editors. 2000. Sensors update. Vol. 7.

8. Trabelsi S, Kraszewski AW, Nelson SO. 1998. A microwave method for on-line determination of bulk density and moisture content of particulate materials. IEEE Trans Instrum Meas 47:127-132.

9. King RJ. "Microwave Reflection Resonator Sensors." U.S. Patent 5,334,941, filed Sep.14, 1992, and issued Aug. 2, 1994.

10. King RJ. 1992. On-line industrial applications of microwave moisture sensors. Sens Update 7, pp.109-170.

11. King RJ. 1996. Microwave characterization using microwave open reflection resonator sensors. In Microwave aqquametryelectromagnetic wave interaction with water-containing materials; Kraszewski AW, Ed., pp.153-175.

12. Heng PWS, Loh ZH, Liew CV, Lee CC. Dielectric properties of pharmaceutical materials relevant to microwave processing: Effects of field frequency, material density, and moisture content. J Pharm Sci 99:941-957.

13. Nelson SO. 1994. Measurement of microwave dielectric properties of particulate materials. J Food Eng 21:365-384.

14. Boyarskii DA, Tikhonov VV, Komarova Yu. 2002. Model of dielectric constant of bound water in soil for applications of microwave remote sensing. Prog Electromag Res 35:251269 . 
15. Chen LF, Ong CK, Neo CP, Varadan VV, Varadan VK. 2004. Microwave electronics-Measurement and materials characterization, pp. 37-42, John Wiley \& Sons Ltd.

16. Rantanen J, Wikström H, Rhea FE, Taylor LS. 2005. Improved understanding of factors contributing to quantification of anhydrate/hydrate powder mixtures. Appl Spectrosc 59:942-951.

17. Meyer W, Schilz W. 1980. A microwave method for density independent determination of the moisture content of solids. J Phys D: Appl Phys 13:1823-1830.

18. Shah KR, Hussain MA, Hubert M, Farag Badawy SI. 2008. Form conversion of anhydrous lactose during wet granulation and its effect on compactibility. Int J Pharm 357:228-234.

19. Buckton G, Yonemochi E, Hammond J, Moffat A. 1998. The use of near infra-red spectroscopy to detect changes in the form of amorphous and crystalline lactose. Int J Pharm 168:231-241.
20. Gupta A, Peck GE, Miller RW, Morris KR. 2005. Influence of ambient moisture on the compaction behavior of microcrystalline cellulose powder undergoing uni-axial compression and roller-compaction: A comparative study using near-infrared spectroscopy. J Pharm Sci 94:2301-2313.

21. Angberg M, Nystru C, Castensson S. 1991. Evaluation of heatconduction microcalorimetry in pharmaceutical stability studies. IV. The influence of microcrystalline cellulose on the hydration rate of anhydrous lactose. Int J Pharm 77:269-277.

22. Sebhatu T, Elamin AA, Ahlneck C. 1994. Effect of moisture sorption on tabletting characteristics of spray dried (15\% amorphous) lactose. Pharm Res 11:1233-1238.

23. Schiffmann RF. 1995. Microwave and dielectric drying. In Handbook of industrial drying; ASMujumdar, Ed. 2nd ed. Vol.1. New York:Marcel Dekker, pp.345-372. 